\title{
Investigating the relationship between insecticide resistance, underlying molecular mechanisms and malaria prevalence in Anopheles gambiae s.l. from Guinea
}

\author{
Emma Collins $^{1+}$, Natasha M. Vaselli ${ }^{1+}$, Moussa Sylla ${ }^{2}$, Abdoul H. Beavogui ${ }^{2}$, James \\ Orsborne $^{1}$, Thomas Walker ${ }^{1}$, Louisa A. Messenger ${ }^{1 *}$ \\ ${ }^{1}$ Department of Disease Control, Faculty of Infectious Tropical Diseases, London School of \\ Hygiene and Tropical Medicine, London, United Kingdom \\ ${ }^{2}$ Centre National de Formation et de Recherche en Santé Rurale de Maferinyah, Maferinyah, \\ Guinea
}

*louisa.messenger@1shtm.ac.uk

+these authors contributed equally to this work

\begin{abstract}
The threat of insecticide resistance across sub-Saharan Africa is anticipated to severely impact the continued effectiveness of malaria vector control. We investigated the effect of carbamate and pyrethroid resistance on Anopheles gambiae s.l age, Plasmodium falciparum infection and characterized molecular resistance mechanisms in Guinea. Pyrethroid resistance was intense, with survivors of ten times the insecticidal concentration required to kill susceptible individuals. The L1014F $k d r$ allele was significantly associated with mosquito survival following deltamethrin or permethrin treatment ( $p=0.003$ and $p=0.04$, respectively). $\mathrm{N} 1575 \mathrm{Y}$ and I1527T mutations were identified in $13 \%$ and $10 \%$ of individuals, respectively, but neither conferred increased pyrethroid tolerance. Partial restoration of pyrethroid susceptibility following synergist pre-exposure suggest a role for mixed-function oxidases. Carbamate resistance was lower and significantly associated with the G119S Ace-1 mutation ( $p=0.001$ ). Oocyst rates were $6.8 \%$ and $4.2 \%$ among resistant and susceptible mosquitoes, respectively; survivors of bendiocarb exposure were significantly more likely to be infected $(p=0.03)$. Resistant mosquitoes had significantly lower parity rates; however, a subset of intensely pyrethroid-resistant vectors were more likely to be parous ( $p=0.042$ and $p=0.045$, for survivors of five and ten times the diagnostic dose of insecticides, respectively). Our findings emphasize the need for additional studies directly assessing the influence of insecticide resistance on mosquito fitness.
\end{abstract}




\section{Introduction}

Malaria remains a leading cause of morbidity and mortality in the tropics, where it is estimated to have resulted in $\sim 445,000$ deaths in 2016 alone ${ }^{1}$. Despite considerable reductions in disease burden achieved by scaling-up the provision of long-lasting insecticidal nets (LLINs) and indoor residual spraying (IRS) ${ }^{2}$, future, long-term effectiveness of both strategies may be jeopardized by widespread emergence of insecticide resistance throughout mosquito populations ${ }^{3,4}$. In response, there is a growing impetus among commercial manufacturers to develop alternate vector control interventions, including novel insecticide classes, combinations and formulations, as well as National Malaria Control Programmes (NMCPs) and international policy makers to expand and heighten resistance monitoring and surveillance ${ }^{5}$. However, the severity of this threat is currently unknown because there is limited evidence linking the operational failure of available control measures to the presence of local, resistant mosquito species $6,7,8,9,10,11,12,13$.

The efficacy of IRS and LLINs is predicated on their ability to reduce the daily survival rate of Anopheles mosquitoes and prevent the completion of parasite development to the infectious stage. In the context of LLINs, one potential explanation for their continued effectiveness in malaria endemic regions, is that intact nets provide a physical barrier to mosquito feeding, even in the presence of increased vector tolerance to their insecticidal properties. A meta-analysis of field data indicate that treated nets reduced blood feeding and increased mosquito mortality compared to untreated nets, even in areas with the highest levels of resistance ${ }^{4}$. Furthermore, a recent large-scale, multi-country trial reported no association between malaria disease burden and pyrethroid resistance, with evidence that LLINs continued to provide personal protection across areas of different resistance intensities ${ }^{14}$. Laboratory studies now suggest that pleiotropic fitness costs associated with insecticide resistance may influence malaria transmission either by directly reducing mosquito life $\operatorname{span}^{15}$ and/or fecundity ${ }^{16}$, altering host seeking, feeding and mating behaviours ${ }^{17} 1819$ or by impairing parasite development inside vectors ${ }^{20} 2122$. However, to date, few field studies have directly investigated the impact of insecticide resistance intensity on malaria transmission dynamics.

In Guinea, malaria represents a significant public health problem, where the entire population of $\sim 11.7$ million people is at risk and the nationwide prevalence is estimated at $15 \%{ }^{23}$.

Between 2013-2017, the NMCP, with support from the President's Malaria Initiative (PMI) and the Global Fund, have procured and distributed over 27.6 million pyrethroid LLINs ${ }^{24}$. Because the current vector control strategy relies almost exclusively on LLIN use ${ }^{25}$, nationwide pyrethroid resistance, is of significant concern ${ }^{26}$. To better inform future malaria control efforts in Guinea, there is a pressing need to characterize levels of operationallysignificant insecticide resistance, as well as determine the effect this phenomenon has on the vectorial capacity of local mosquitoes to transmit malaria. 


\section{Results}

Mosquito abundance and species identification

A total of 3962 female An. gambiae s.l. mosquitoes were captured from six sites in

Maferinyah subprefecture, in Forecariah Prefecture (Senguelen=766; Yindi=755; Maferinyah Centre I=660; Madinagbe=608; Fandie=608 and Moribayah=565) over 25 days by manual aspiration from houses and human landing catches. A subsample of 181 were selected for molecular form identification, of which 68\% (123/181) and 31\% (56/181) were determined to be An. coluzzii (M molecular form) and An. gambiae s.s. (S molecular form), respectively; two hybrid forms (An. gambiae-An. coluzzii) were also identified. While both molecular forms were sympatric across Forecariah Prefecture, proportions did differ significantly among study villages $\left(\chi^{2}=26.99 ; p=0.003\right)$, potentially attributable to varying local ecological factors favoured by each form ${ }^{27}$ (Figure 1A).

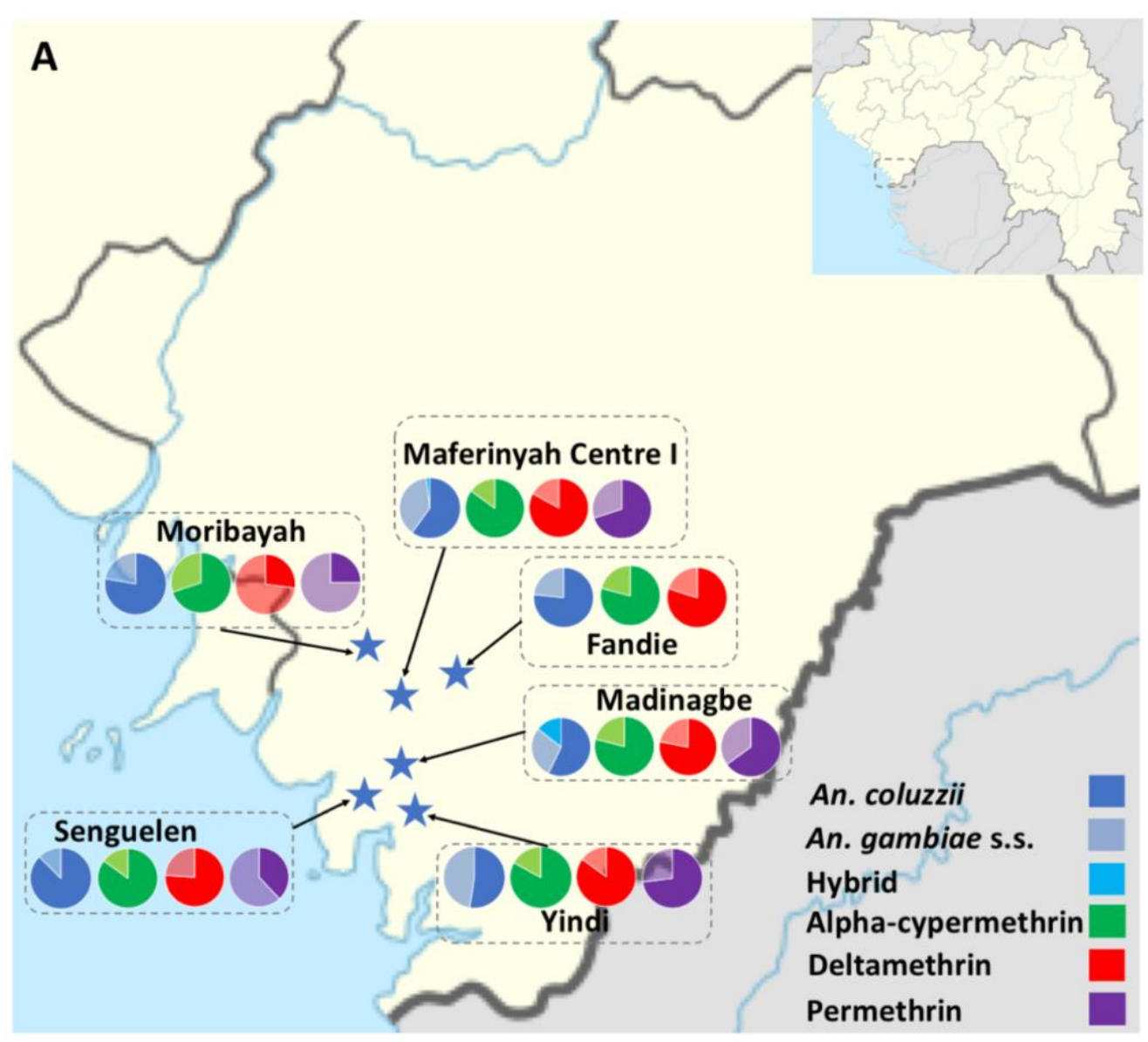




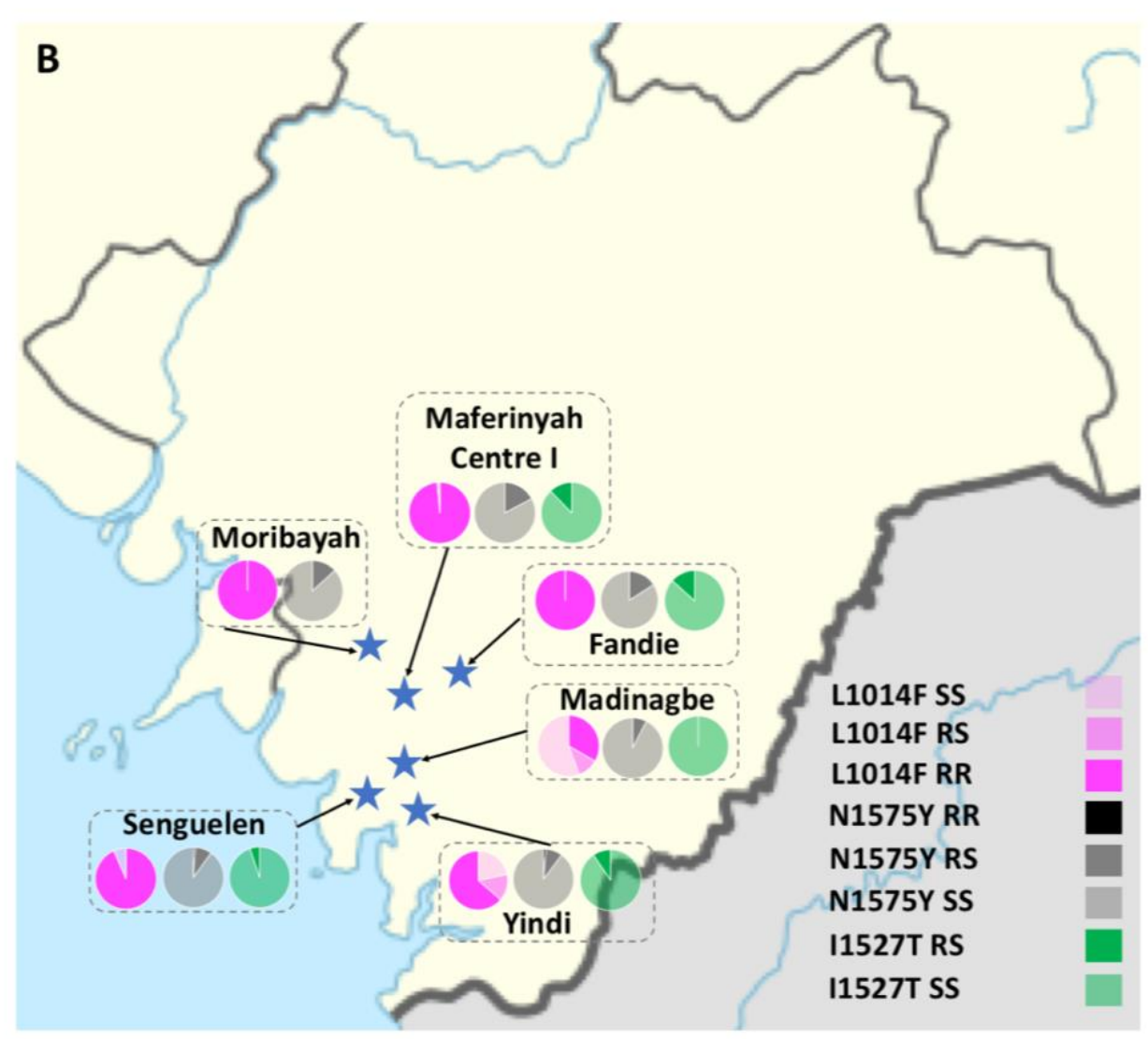




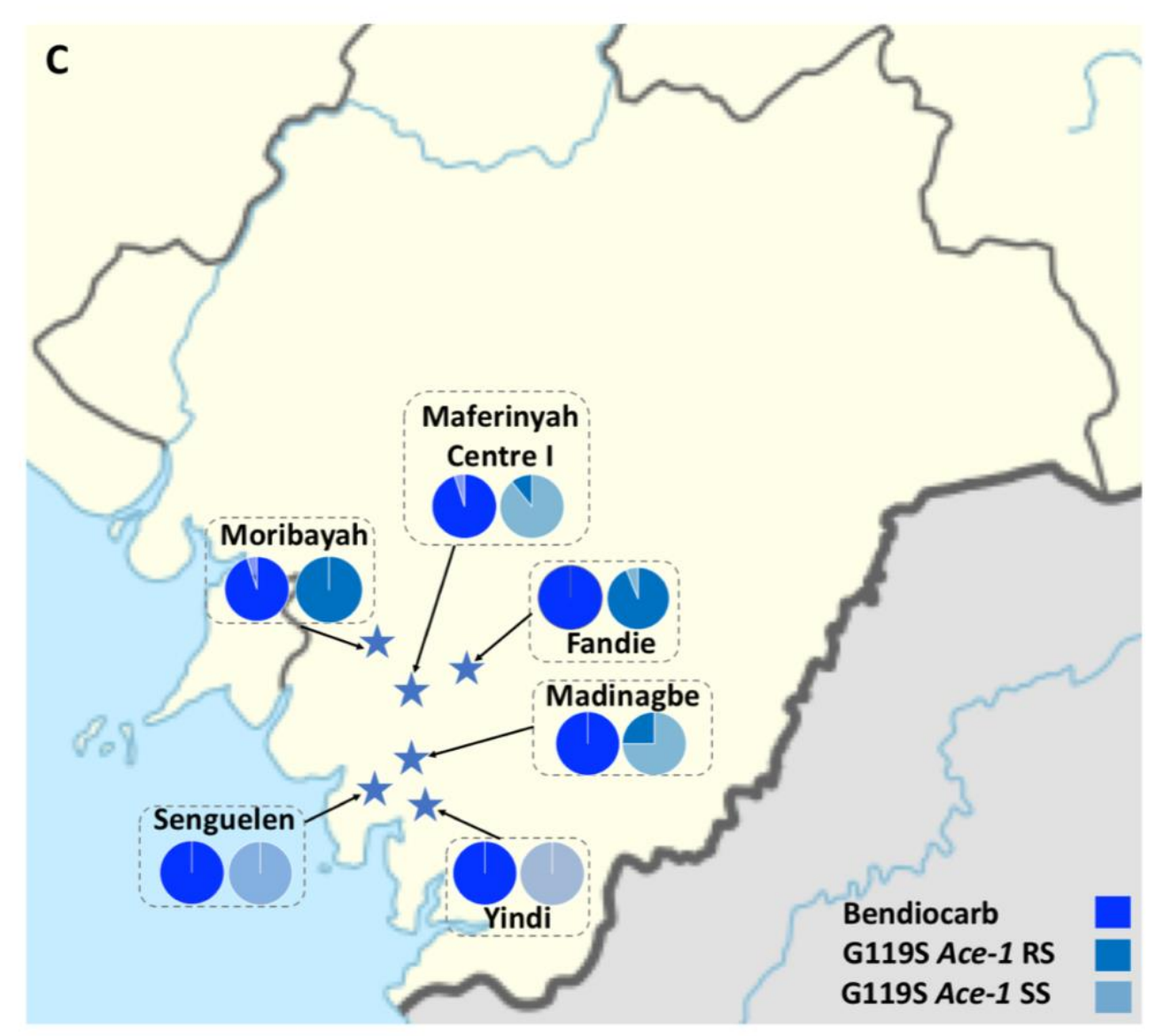

Figure 1. A: Map of Forecariah Prefecture, Guinea displaying proportions of An. gambiae s.l. molecular forms and susceptibility levels to the diagnostic dose (1X) of alphacypermethrin, deltamethrin and permethrin, measured using CDC bottle bioassays, at six study sites indicated by stars (Fandie, Madinagbe, Maferinyah Centre I, Moribayah, Senguelen and Yindi). Inset map shows the location of Forecariah Prefecture in Guinea. B: Map of Forecariah Prefecture, Guinea displaying frequencies of L1014F, N1575Y and I1527T resistant (R) and wild type (S) alleles. C: Map of Forecariah Prefecture, Guinea displaying susceptibility levels to the diagnostic dose (1X) of bendiocarb, measured using CDC bottle bioassays, and frequency of G119S Ace-1 resistant (R) and wild type (S) alleles. For all maps, legend colours referring to insecticides have darker shading denoting average mosquito mortality.

\section{Insecticide resistance intensity}

Levels of resistance to four insecticides (alpha-cypermethrin, bendiocarb, deltamethrin and permethrin) were assessed among 2229 female An. gambiae s.l. mosquitoes, collected across six study sites in Forecariah Prefecture (Figure 1A and Figure 1C). Local vectors were characterized by intense but highly variable pyrethroid resistance, with all populations demonstrating less than $90 \%$ mosquito mortality to the diagnostic doses of pyrethroids and most areas containing individuals capable of surviving exposure to ten times these insecticide concentrations (Table 1 and Figure 2). In addition, a subsample of mosquitoes still living 
following 30 minutes of insecticide exposure were held for up to two hours in treated bottles, with more than $30 \%$ of vectors capable of surviving this extended exposure time in Madinagbe (17/55) Moribayah (19/38), Seneguelen (30/82) and Yindi (9/27); there was no significant difference in survival at two hours between the three pyrethroids under evaluation $\left(\chi^{2}=4.35 ; p=0.114\right)$. A significant decline in proportions of mosquitoes surviving two hours of pyrethroid exposure was observed with increasing insecticide concentration; $37 \%$ (38/102), 25\% (24/95), 26\% (21/81) and 10\% (5/52) of individuals survived contact with $1 \mathrm{X}$, $2 \mathrm{X}, 5 \mathrm{X}$ and $10 \mathrm{X}$ for two hours $\left(\chi^{2}=13.70 ; p=0.003\right)$, respectively. The highest levels of pyrethroid resistance were observed in Moribayah, where mosquito mortality to two times the diagnostic doses of deltamethrin and permethrin was $38 \%$ and $32 \%$, respectively (Table 1). In general, levels of resistance were greater to permethrin compared to alpha-cypermethrin or deltamethrin, e.g. in Senguelen mosquito mortality was 38\% vs. 85\% and 76\%, respectively.

By comparison, levels of carbamate resistance were low, with complete mosquito susceptibility observed in Fandie, Madinagbe, Senguelen and Yindi; possible resistance (95\% mosquito mortality) was restricted to two adjacent villages (Maferinyah Centre I and Moribayah) (Figure 1C and Table 1).

For all insecticides, there was no significant difference in ability to survive exposure between An. coluzzii and An. gambiae s.s. $\left(\chi^{2}=3.60 ; p=0.165\right)$ or association with survival and physiological status (i.e. blood-fed, unfed, gravid, etc.) $\left(\chi^{2}=0.76 ; p=0.999\right)$. 
Table 1. Percentage corrected mortality (and numbers tested) of Anopheles gambiae s.l. in CDC resistance intensity and synergist assays conducted in six sites in Forecariah Prefecture, Guinea.

\begin{tabular}{|c|c|c|c|c|c|}
\hline \multirow[b]{2}{*}{ Study Site } & \multirow[b]{2}{*}{ Insecticides } & \multicolumn{4}{|c|}{ \% Mortality (numbers tested) after the diagnostic time } \\
\hline & & $1 \mathrm{X}$ & $2 \mathrm{X}$ & $5 \mathrm{X}$ & $10 \mathrm{X}$ \\
\hline \multirow{4}{*}{ Fandie } & Alpha-cypermethrin & $79(19)$ & $86(21)$ & $83(23)$ & $89(19)$ \\
\hline & Alpha-cypermethrin + PBO & $91(22)$ & $95(19)$ & $95(22)$ & $100(13)$ \\
\hline & Bendiocarb & $100(23)$ & - & - & - \\
\hline & Deltamethrin & $80(20)$ & $78(22)$ & $74(19)$ & $95(20)$ \\
\hline \multirow{4}{*}{ Madinagbe } & Alpha-cypermethrin & $79(24)$ & $80(25)$ & $88(24)$ & $88(17)$ \\
\hline & Bendiocarb & $100(19)$ & - & - & - \\
\hline & Deltamethrin & $78(23)$ & $89(19)$ & $89(18)$ & $86(21)$ \\
\hline & Permethrin & $65(20)$ & $71(21)$ & $78(27)$ & $78(18)$ \\
\hline \multirow{4}{*}{ Maferinyah Centre I } & Alpha-cypermethrin & $85(41)$ & $98(43)$ & $94(46)$ & $87(38)$ \\
\hline & Bendiocarb & $95(40)$ & - & - & - \\
\hline & Deltamethrin & $83(35)$ & $89(35)$ & $83(35)$ & $97(35)$ \\
\hline & Permethrin & $70(20)$ & $95(20)$ & $100(21)$ & $95(20)$ \\
\hline \multirow{4}{*}{ Moribayah } & Alpha-cypermethrin & $70(20)$ & $86(21)$ & $82(22)$ & $87(23)$ \\
\hline & Bendiocarb & $95(20)$ & - & - & - \\
\hline & Deltamethrin & $27(22)$ & $38(21)$ & $86(22)$ & $88(16)$ \\
\hline & Permethrin & $25(24)$ & $32(25)$ & $86(22)$ & $95(20)$ \\
\hline \multirow{5}{*}{ Seneguelen } & Alpha-cypermethrin & $85(41)$ & $88(41)$ & $92(37)$ & $93(43)$ \\
\hline & Bendiocarb & $100(22)$ & - & - & - \\
\hline & Deltamethrin & $76(42)$ & $77(44)$ & $86(42)$ & $83(41)$ \\
\hline & Deltamethrin + PBO & $81(16)$ & $88(16)$ & 89 (19) & $100(11)$ \\
\hline & Permethrin & $38(29)$ & $40(25)$ & $96(25)$ & $100(19)$ \\
\hline \multirow{4}{*}{ Yindi } & Alpha-cypermethrin & $83(42)$ & $95(43)$ & $90(30)$ & $92(25)$ \\
\hline & Bendiocarb & $100(22)$ & - & - & - \\
\hline & Deltamethrin & $85(40)$ & $90(39)$ & $92(36)$ & $95(42)$ \\
\hline & Permethrin & $73(45)$ & $89(36)$ & $92(36)$ & $100(35)$ \\
\hline
\end{tabular}




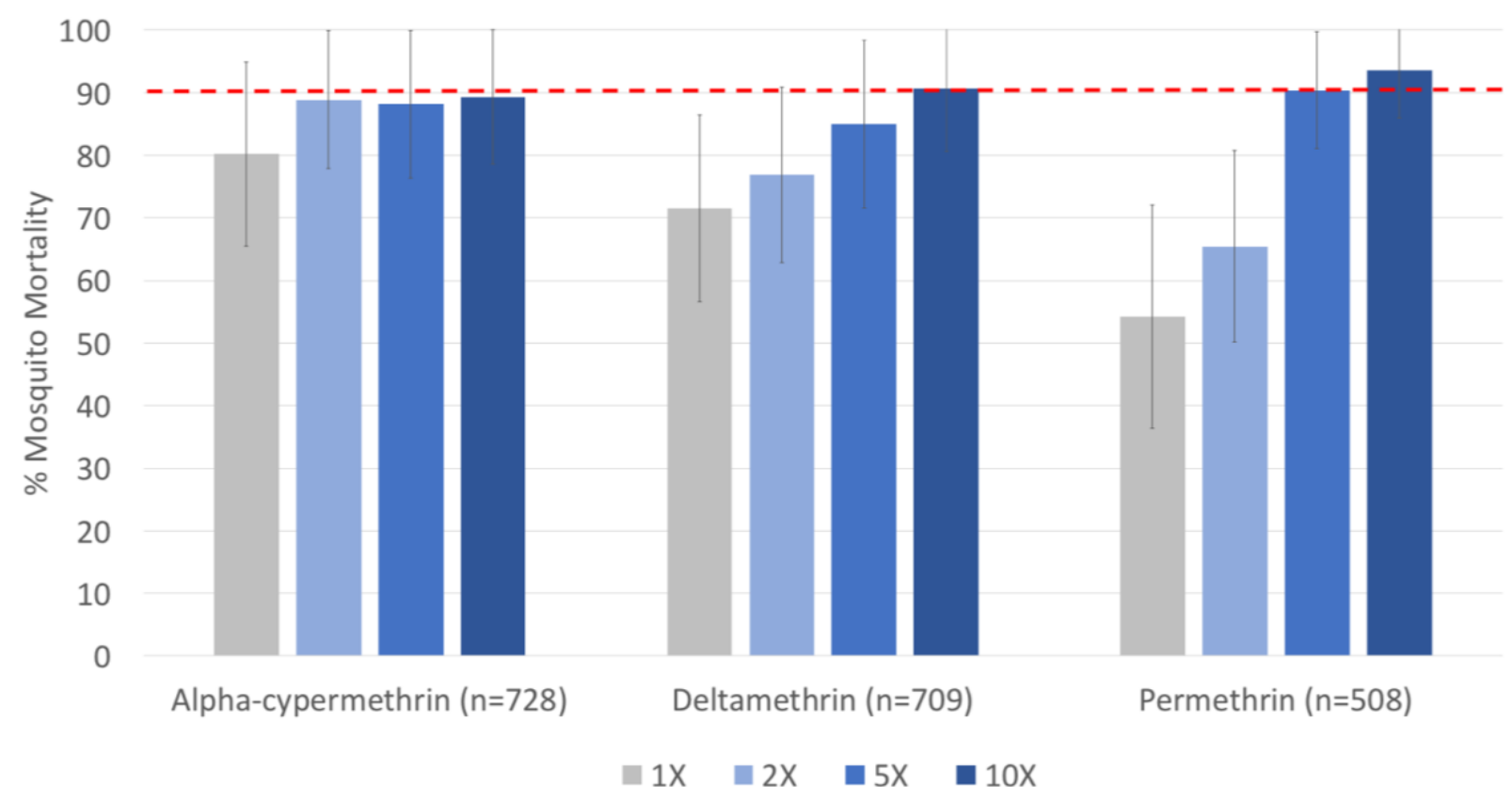

Figure 2. CDC resistance intensity assay data for three pyrethroid insecticides (alphacypermethrin, deltamethrin and permethrin) pooled across six study sites in Forecariah Prefecture (Fandie, Madinagbe, Maferinyah Centre I, Moribayah, Senguelen and Yindi). Mortality below $90 \%$ (indicated by the dashed red line) indicates the presence of confirmed resistance.

\section{Mosquito parity}

Of 737 An. gambiae s.l. mosquitoes tested in resistance bioassays, which had their ovaries inspected for parity, $46 \%$ were nulliparous (340/737), i.e. had not laid an egg batch, and 54\% (397/737) were parous. There was no significant difference in proportion of parous mosquitoes by study village $\left(\chi^{2}=2.70 ; p=0.75\right)$. However, for all three pyrethroids under evaluation, resistant mosquitoes were significantly more likely to be nulliparous (alphacypermethrin: $\chi^{2}=15.59 ; p<0.0000$; deltamethrin: $\chi^{2}=8.05 ; p=0.005$; and permethrin: $\left.\chi^{2}=8.69 ; p=0.003\right)$. Small sample numbers precluded a direct comparison between pyrethroid resistance intensity and parity per insecticide, but when considering resistance levels of all pyrethroids, mosquitoes which were resistant to lower insecticide concentrations $(2 \mathrm{X})$ were significantly more likely to be nulliparous $\left(\chi^{2}=17.78 ; p<0.0001\right)$, while greater proportions of those surviving exposure to five and ten times the diagnostic doses were parous $\left(\chi^{2}=4.13\right.$; $p=0.042$ and $\chi^{2}=4.03 ; p=0.045$, respectively). Similarly, survivors of exposure to the diagnostic dose $(1 \mathrm{X})$ of bendiocarb were significantly more likely to be nulliparous $\left(\chi^{2}=3.75\right.$; $p=0.05)$.

\section{Target site and metabolic mechanisms of resistance}

N1575Y mutation screening was undertaken in a subset of 388 An. gambiae s.l. and was detected in 13\% (49/388) of samples in both An. coluzzii and An. gambiae s.s.; only two homozygote individuals were detected (Figure 1B and Table 2). The frequency of the 
N1575Y resistant allele varied non-significantly both among study districts, from 0.04 in Madinagbe to 0.09 in Maferinyah Centre I $\left(\chi^{2}=8.34 ; p=0.60\right)$ (Table 2 and Figure $\left.1 \mathrm{~B}\right)$, and between mosquitoes surviving and dying in pyrethroid bioassays, respectively $\left(\chi^{2}=2.05\right.$; $p=0.36$ ). There was no significant association between N1575Y allele frequency and ability of mosquitoes to survive pyrethroid exposure (alpha-cypermethrin: $\chi^{2}=1.58 ; p=0.45$; deltamethrin: $\chi^{2}=0.79 ; p=0.375$ and permethrin: $\left.\chi^{2}=1.52 ; p=0.22\right)$ or extended two hour pyrethroid exposure $\left(\chi^{2}=2.47 ; p=0.29\right)$.

One hundred and twenty-eight base pairs upstream of N1575Y, a second non-synonymous mutation (I1527T) was identified among 10\% of individuals (11/109); this mutation was not linked to N1575Y and only one individual from Maferinyah Centre I had both resistance mutations. All individuals with the I1527T resistant allele were heterozygous for this mutation and were identified as An. gambiae s.s. The frequency of the L1527T resistant allele varied non-significantly among study villages $\left(\chi^{2}=1.48 ; p=0.83\right)$, ranging from 0 in Madinagbe to 0.07 in Fandie (Table 3 and Figure 1B). There was no significant association between I1527T allele frequency and ability of mosquitoes to survive pyrethroid exposure (alpha-cypermethrin: $\chi^{2}=0.04 ; p=0.84$; deltamethrin: $\chi^{2}=0.22 ; p=0.64$ and permethrin: $\left.\chi^{2}=2.94 ; p=0.09\right)$ or extended two hour pyrethroid exposure $\left(\chi^{2}=0.13 ; p=0.72\right)$.

The presence of L1014F $k d r$ allele was identified among $87 \%$ of samples (211/242), with the majority of mosquitoes presenting homozygous $k d r$ profiles $(83 \% ; 200 / 242)$. The frequency of the L1014F $k d r$ resistant allele varied significantly among study villages $\left(\chi^{2}=93.82\right.$; $p<0.0001$ ), ranging from 0.39 in Madinagbe to 1.0 in Fandie and Moribayah (Table 4 and Figure 1B). There was a significant association between L1014F $k d r$ allele frequency and ability of mosquitoes to survive deltamethrin or permethrin exposure $\left(\chi^{2}=11.72 ; p=0.003\right.$ and $\chi^{2}=6.39 ; p=0.04$, respectively); however, this did not extend to survival after two hours of either insecticide treatment $\left(\chi^{2}=1.45 ; p=0.48\right.$ and $\chi^{2}=3.87 ; p=0.14$, respectively). No significant association with the L1014F $k d r$ allele frequency and ability to survive alphacypermethrin exposure was observed $\left(\chi^{2}=1.67 ; p=0.43\right)$.

The presence of G119S Ace-1 mutation was identified among 10\% of samples (7/67) (Figure 1C). All individuals with the resistant allele were heterozygous for this mutation and were identified as An. gambiae s.s. Frequencies of the G119S Ace-1 mutation varied significantly among study districts ranging from 0 in Senguelen and Yindi to 0.5 in Moribayah $\left(\chi^{2}=20.34\right.$; $p=0.001$ ) (Table 5 and Figure 1C). There was a significant association between presence of the G119S Ace-1 mutation and ability of mosquitoes to survive 30 minute and two hour carbamate exposure $\left(\chi^{2}=11.51 ; p=0.001\right.$ and $\chi^{2}=18.63 ; p<0.0001$, respectively).

Across Forecariah Prefecture, significant deviations from Hardy-Weinberg equilibrium were observed for L1014F $k d r$ in Madinagbe, Maferinyah Centre I, Senguelen and Yindi $(p<0.0001$ for all) (Table 4$)$ but not for any other resistance loci.

Finally, to confirm the potential role of cytochrome P450 enzymes in pyrethroid resistance, mosquitoes collected in Fandie and Senguelen were pre-exposed to piperonyl butoxide (PBO), prior to intensity testing with alpha-cypermethrin and deltamethrin, respectively. In both populations, susceptibility was partially restored at five times the diagnostic dose of pyrethroids (95\% and $89 \%$ mosquito mortality to alpha-cypermethrin and deltamethrin, respectively) and fully restored at 10X (Table 1). 
Table 2. N1575Y allele frequencies in An. gambiae s.l. from six study sites in Forecariah Prefecture, Guinea.

\begin{tabular}{|c|c|c|c|c|c|c|c|c|}
\hline \multirow[t]{2}{*}{ Study Site } & \multirow{2}{*}{$\begin{array}{c}\# \\
\text { Mosquitoes } \\
\text { tested }\end{array}$} & \multirow{2}{*}{$\begin{array}{c}\text { Homozygote } \\
\text { mutation } \\
\text { (RR) }\end{array}$} & \multirow{2}{*}{$\begin{array}{l}\text { Heterozygote } \\
\text { mutation } \\
\text { (RS) }\end{array}$} & \multirow{2}{*}{$\begin{array}{c}\text { Homozygote } \\
\text { wild type } \\
\text { (SS) }\end{array}$} & \multicolumn{2}{|c|}{$\begin{array}{l}\text { N1575Y allele } \\
\text { frequency }\end{array}$} & \multirow[b]{2}{*}{$\chi^{2}$ Test } & \multirow[b]{2}{*}{$P$ value } \\
\hline & & & & & $\boldsymbol{R}$ & $S$ & & \\
\hline Fandie & 63 & 0 & 10 & 53 & 0.08 & 0.92 & 0.47 & 0.493 \\
\hline Madinagbe & 40 & 0 & 3 & 37 & 0.04 & 0.96 & 0.06 & 0.807 \\
\hline Maferinyah Centre I & 87 & 0 & 15 & 72 & 0.09 & 0.91 & 0.77 & 0.380 \\
\hline Moribayah & 38 & 0 & 5 & 33 & 0.07 & 0.93 & 0.19 & 0.663 \\
\hline Seneguelen & 91 & 1 & 8 & 82 & 0.05 & 0.05 & 2.14 & 0.144 \\
\hline Yindi & 69 & 1 & 6 & 62 & 0.06 & 0.94 & 2.87 & 0.090 \\
\hline
\end{tabular}

Table 3. I1527T allele frequencies in An. gambiae s.l. from five study sites in Forecariah Prefecture, Guinea.

\begin{tabular}{|c|c|c|c|c|c|c|c|c|}
\hline \multirow[t]{2}{*}{ Study Site } & \multirow{2}{*}{$\begin{array}{c}\# \\
\text { Mosquitoes } \\
\text { tested }\end{array}$} & \multirow{2}{*}{$\begin{array}{l}\text { Homozygote } \\
\text { mutation } \\
\text { (RR) }\end{array}$} & \multirow{2}{*}{$\begin{array}{c}\text { Heterozygote } \\
\text { mutation } \\
(\mathrm{RS})\end{array}$} & \multirow{2}{*}{$\begin{array}{c}\text { Homozygote } \\
\text { wild type } \\
\text { (SS) }\end{array}$} & \multicolumn{2}{|c|}{$\begin{array}{l}\text { I1527T allele } \\
\text { frequency }\end{array}$} & \multirow[b]{2}{*}{$\chi 2$ Test } & \multirow[b]{2}{*}{$P$ value } \\
\hline & & & & & $\boldsymbol{R}$ & $S$ & & \\
\hline Fandie & 15 & 0 & 2 & 13 & 0.07 & 0.93 & 0.08 & 0.777 \\
\hline Madinagbe & 5 & 0 & 0 & 5 & 0 & 1.0 & - & - \\
\hline Maferinyah Centre I & 49 & 0 & 6 & 43 & 0.06 & 0.94 & 0.21 & 0.647 \\
\hline Seneguelen & 19 & 0 & 1 & 18 & 0.03 & 0.97 & 0.01 & 0.920 \\
\hline Yindi & 21 & 0 & 2 & 19 & 0.05 & 0.95 & 0.05 & 0.823 \\
\hline
\end{tabular}


Table 4. L1014F kdr allele frequencies in An. gambiae s.l. from six study sites in Forecariah Prefecture, Guinea.

\begin{tabular}{|c|c|c|c|c|c|c|c|c|}
\hline \multirow[t]{2}{*}{ Study Site } & \multirow{2}{*}{$\begin{array}{c}\# \\
\text { Mosquitoes } \\
\text { tested }\end{array}$} & \multirow{2}{*}{$\begin{array}{l}\text { Homozygote } \\
\text { mutation } \\
\text { (RR) }\end{array}$} & \multirow{2}{*}{$\begin{array}{l}\text { Heterozygote } \\
\text { mutation } \\
\text { (RS) }\end{array}$} & \multirow{2}{*}{$\begin{array}{l}\text { Homozygote } \\
\text { wild type } \\
\text { (SS) }\end{array}$} & \multicolumn{2}{|c|}{$\begin{array}{l}\mathrm{L1014F} \boldsymbol{k d r} \\
\text { allele frequency }\end{array}$} & \multirow[b]{2}{*}{$\chi^{2}$ Test } & \multirow[b]{2}{*}{$P$ value } \\
\hline & & & & & $R$ & $S$ & & \\
\hline Fandie & 38 & 38 & 0 & 0 & 1.0 & 0 & - & - \\
\hline Madinagbe & 27 & 9 & 3 & 15 & 0.39 & 0.61 & 15.85 & $<0.0001$ \\
\hline Maferinyah Centre I & 70 & 69 & 0 & 1 & 0.99 & 0.01 & 70.00 & $<0.0001$ \\
\hline Moribayah & 6 & 6 & 0 & 0 & 1.0 & 0 & - & - \\
\hline Seneguelen & 46 & 43 & 0 & 3 & 0.93 & 0.07 & 46.00 & $<0.0001$ \\
\hline Yindi & 55 & 35 & 8 & 12 & 0.71 & 0.29 & 23.05 & $<0.0001$ \\
\hline
\end{tabular}

Table 5. G119S Ace-1 allele frequencies in An. gambiae s.l. from six study sites in Forecariah Prefecture, Guinea.

\begin{tabular}{|c|c|c|c|c|c|c|c|c|}
\hline \multirow[t]{2}{*}{ Study Site } & \multirow{2}{*}{$\begin{array}{c}\# \\
\begin{array}{c}\text { Mosquitoes } \\
\text { tested }\end{array}\end{array}$} & \multirow{2}{*}{$\begin{array}{c}\text { Homozygote } \\
\text { mutation } \\
\text { (RR) }\end{array}$} & \multirow{2}{*}{$\begin{array}{c}\text { Heterozygote } \\
\text { mutation } \\
(\mathrm{RS})\end{array}$} & \multirow{2}{*}{$\begin{array}{l}\text { Homozygote } \\
\text { wild type } \\
\text { (SS) }\end{array}$} & \multicolumn{2}{|c|}{$\begin{array}{l}\text { G119S Ace-1 allele } \\
\text { frequency }\end{array}$} & \multirow[b]{2}{*}{$\chi^{2}$ Test } & \multirow[b]{2}{*}{$P$ value } \\
\hline & & & & & $R$ & $S$ & & \\
\hline Fandie & 16 & 0 & 1 & 15 & 0.03 & 0.97 & 0.02 & 0.888 \\
\hline Madinagbe & 4 & 0 & 1 & 3 & 0.13 & 0.88 & 0.08 & 0.777 \\
\hline Maferinyah Centre I & 28 & 0 & 3 & 25 & 0.05 & 0.95 & 0.09 & 0.764 \\
\hline Moribayah & 2 & 0 & 2 & 0 & 0.5 & 0.5 & 2.00 & 0.157 \\
\hline Seneguelen & 9 & 0 & 0 & 9 & 0.0 & 1.0 & - & - \\
\hline Yindi & 8 & 0 & 0 & 8 & 0.0 & 1.0 & - & - \\
\hline
\end{tabular}




\section{Plasmodium falciparum infection and infectivity}

The abdomens and head/thoraxes of 484 An. gambiae s.l. were screened separately to detect the presence of Plasmodium falciparum oocysts and sporozoites, respectively. Overall oocyst and sporozoite rates were $6.0 \%$ (29/484) and $0.2 \%(1 / 484)$, respectively. There was no significant difference in oocyst rate among study villages $\left(\chi^{2}=7.71 ; p=0.173\right)$ or molecular forms $\left(\chi^{2}=0.25 ; p=0.88\right)$. In mosquitoes which survived insecticide exposure, oocyst rate was $6.8 \%(23 / 340)$ compared to $4.2 \%(6 / 144)$ among their susceptible counterparts, respectively. The single sporozoite positive individual was collected from Maferinyah Centre I and died following $2 \mathrm{X}$ alpha-cypermethrin exposure.

Considering the interaction between pyrethroid resistance and $P$. falciparum infection, there was no significant relationship between oocyst rate and survival following insecticide exposure in all pooled data $\left(\chi^{2}=0.26 ; p=0.61\right)$ or per insecticide (alpha-cypermethrin: $\chi^{2}=0.16 ; p=0.69$; deltamethrin: $\chi^{2}=0.07 ; p=0.79$ and permethrin: $\chi^{2}=2.28 ; p=0.13$ ). Considering the interaction between carbamate resistance and $P$. falciparum infection, survivors of bendiocarb exposure were significantly more likely to be infected with oocysts $\left(\chi^{2}=4.86 ; p=0.03\right)$.

No significant associations were observed between presence of resistance mutations and oocyst positivity $\left(\chi^{2}=0.67, p=0.72 ; \chi^{2}=0.35, p=0.56, \chi^{2}=2.14 ; p=0.34\right.$ and $\chi^{2}=0.27 ; p=0.60$, for N1575Y, I1527T, L1014F $k d r$ and G119S Ace-1, respectively).

\section{Discussion}

By 2016, resistance to at least one insecticide has been reported from over $80 \%$ of malaria endemic countries ${ }^{1}$, representing a significant threat to the continued efficacy of key malaria control strategies. However, the relative impact of decreased mosquito susceptibility on vectorial capacity remains unknown, largely due to a paucity of field data. In an area of high malaria transmission in Guinea, we characterized levels of insecticide resistance and age of local vector populations, in combination with molecular identification of resistance markers and detection of malaria infection, to begin to address this deficit.

In Forecariah Prefecture, intense pyrethroid resistance was abundant, evidenced by vector populations which were not only resistant to ten times the insecticide concentration required to kill susceptible individuals, but were also capable of surviving these doses for up to two hours. These observations are of significant concern given the coverage of pyrethroid LLINs has been scaled-up in this area. The restoration of mosquito susceptibility following preexposure to PBO and the association of L1014F $k d r$ with levels of mortality to deltamethrin and permethrin suggests that both target site mutations and over-expression of $\mathrm{P} 450$ monooxygenases are contributing to pyrethroid resistance. By comparison, N1575Y and I1527T allele frequencies were lower and neither were associated with increased survival following pyrethroid treatment. This finding aligns with reports from Burkina Faso where upregulated detoxification enzymes were responsible for extreme pyrethroid resistance in $A n$. coluzzii, with $\mathrm{N} 1575 \mathrm{Y}$ associated with more limited tolerance to deltamethrin ${ }^{28}$. Other studies have proposed that N1575Y may compensate for fitness costs incurred by the L1014F $k d r$ mutation and provide additional pyrethroid resistance ${ }^{29}$. The I1527T mutation is located within the III S6 helix of the voltage-gated sodium channel gene, adjacent to a predicted pyrethroid/DDT binding site; nearby residues have already been implicated in resistance in 
other medically-important vector species ${ }^{30,31}$. However, to date, a role for I1527T in phenotypic resistance in An. gambiae s.l. has not been confirmed. While not currently under selection in our study area, future surveillance efforts may wish to monitor changing frequencies of N1575Y and I1527T, in lieu of L1014F $k d r$, which is closely approaching fixation in the majority of our populations, to assess the effect vector interventions are having on the evolution of local, contemporary pyrethroid resistance.

Of the three pyrethroid insecticides under evaluation, resistance levels were highest to permethrin, despite all mass net campaigns in the country having exclusively distributed deltamethrin-treated products ${ }^{24}$. This may be explained by L1014F $k d r$ playing a larger contributing role to resistance to type I (permethrin) versus type II (alpha-cypermethrin and deltamethrin) pyrethroids ${ }^{32}$. Levels of bendiocarb resistance were comparatively lower, and not unexpected considering IRS is not routinely conducted by the Guinean NMCP. In the case of carbamate resistance, the presence of the G119S Ace-1 mutation was highly predictive of bioassay survivorship and tolerance to increased exposure times. Previous studies have demonstrated that the G119S substitution imposes a high fitness $\operatorname{cost}^{33}{ }^{34}$ by decreasing affinity of the resistant enzyme for its substrate by more than $60 \%$; heterogeneous or homogeneous duplication of this locus has been proposed to restore activity $^{36}$. In Forecariah Prefecture, frequency of the G119S Ace-1 resistant allele (of undetermined copy number) was low and likely a result of selective pressure imposed by unregulated agricultural use of carbamates and organophosphates, which were readily available at the local market (S. Irish, personal communication).

Our results demonstrated that pyrethroid resistance was not associated with lower malaria prevalence rates in mosquitoes, with no significant differences observed between rates of Plasmodium infection among susceptible and resistant individuals. Our findings contrast with a number of laboratory studies ascribing potential fitness costs to vector insecticide resistance which may have the collateral benefit of reducing malaria transmission 151718192021 . More worryingly, in our study, survivors of bendiocarb exposure were significantly more likely to be infected with Plasmodium oocysts. Pyrethroid exposure has previously been shown to adversely affect $P$. falciparum development in L1014F $k d r$ resistant An. gambiae s.s. in Uganda $^{20}$, which may explain part of our data, if we assume resistant individuals are frequently surviving contact with LLINs and susceptible vectors are not. Alternative observations have also been reported; $k d r$ mutation has been shown to potentiate the vector competence of An. gambiae s.s. ${ }^{22}$, Plasmodium infection has partially restored the susceptibility of An. gambiae carrying the $k d r$ mutation to $\mathrm{DDT}^{37}$ but also reduced the survival of resistant vectors in the absence of insecticide exposure ${ }^{16}$. The discrepancies between in vitro studies and our field data may reflect more generalised fitness variation between laboratory mosquito strains and wild populations and/or different underlying resistance mechanisms, e.g. target site mutations $v s$. over-expression of metabolic enzymes, and strongly support the need for additional studies in areas of differing resistance and disease transmission intensities.

We chose to examine the impact of resistance on mosquito age as increasing age has been proposed to restore insecticide susceptibility 38394041424344 and insecticide exposure may still reduce resistant vector life-span through delayed mortality effects ${ }^{15}$. In Forecariah Prefecture, resistant mosquitoes had significantly lower parity rates than their susceptible counterparts. However, a small proportion of those displaying intense resistance (i.e. were capable of surviving exposure to five and ten times the diagnostic dose of pyrethroids) were more likely to be parous. Without additional vector life history information, it is impossible 
to distinguish between correlation and causality in this scenario. It is tempting to speculate that this small proportion of highly-resistant mosquitoes either evaded or were capable or surviving insecticide exposure for long enough to lay an egg batch. Alternatively, this population could have consisted of more moderately-resistant vectors which underwent multiple sub-lethal contact events, in turn conflating their levels of pyrethroid resistance intensity ${ }^{45}$.

Elucidating the interaction between insecticide resistance and vectorial capacity is complex and challenging in field conditions and a number of limitations were encountered during this study. Adult female mosquitoes were sampled using human landing catches (HLCs) and via manual aspiration from house walls to maximise the number of individuals available for bioassay testing. However, these strategies may have introduced a bias in species composition collected; previous studies have suggested that proportions of An. gambiae s.s. and $A n$. coluzzii may differ significantly between larval and adult spray catches ${ }^{46}$. We also encountered issues with individuals that did not amplify with two sub-species PCR assays $^{47,48}$, potentially reflecting polymorphisms at the primer binding sites and/or the presence of a cryptic sub-species; previously a cryptic subgroup GOUNDRY has been reported, with close genetic affinities to $A n$. coluzzii and enhanced susceptibility to $P$. falciparum infection ${ }^{49-51}$. While it is recommended to use $\mathrm{F}_{1}$ progeny mosquitoes for resistance testing ${ }^{52}{ }^{53}$, to investigate the impact of resistance on vector Plasmodium infection, it was necessary to sample wild caught adults of undetermined, mixed age and physiological status (i.e. unfed, fed, gravid etc.); the latter parameter may have varied between sampling method, with more fed mosquitoes collected from inside houses, compared to unfed, hostseeking mosquitoes in HLCs. As a consequence, mortality in our study may have been underestimated, considering the proposed inverse relationship between vector resistance and age ${ }^{38}$ 394041424344 . Similarly, blood-feeding among resistant mosquitoes has been suggested to increase insecticide tolerance ${ }^{54}$, however, it should be noted that no association between physiological status and resistance was observed in our dataset. Our study would have also benefitted from larger sample sizes of mosquitoes tested in bioassays, to statistically power comparisons between different resistance intensities. Furthermore, oocyst positive mosquitoes cannot all be assumed to become infective sporozoite-transmitters, particularly if vector life-span is reduced; it is important to note that a positive abdomen can also reflect a recent feed on an infected individual. Finally, manual parity dissections have a number of known constraints, including insensitivity, especially in low endemicity areas, and interoperator subjectivity. While every effort was made to consistently bisect individuals, and our reported sporozoite rate was low, other studies have demonstrated higher number of sporozoite false positives by PCR when abdomens were removed posterior to the junction of the abdomen and thorax ${ }^{55}$.

\section{Conclusions}

Study findings present a comprehensive overview of the current levels of insecticide resistance and underlying target site mutations present in Maferinyah, Guinea, an area of high malaria transmission. We describe a methodology to unravel the interaction between insecticide resistance and malaria transmission dynamics, with putative implications for the operational effectiveness of vector control interventions. Local mosquito populations were intensely resistant to pyrethroids (alpha-cypermethrin, deltamethrin and permethrin), associated with high frequencies of the L1014F $k d r$ allele. N1575Y and I1527T mutations in the voltage-gated sodium channel gene were present at lower levels and may warrant 
increased surveillance efforts, particularly as L1014F $k d r$ approaches fixation. Restoration of mosquito susceptibility following pre-exposure to PBO indicates upregulated detoxification enzymes are also responsible for extreme pyrethroid resistance in this area and require additional characterization. Despite no ongoing vector control activities using carbamates, bendiocarb resistance was also detected, mediated by the G119S Ace-1 mutation in a subset of tolerant individuals. Malaria infection (oocyst rate) was not associated with pyrethroid resistance, potentially attributable to the influence chemical exposure may have on parasite development. In general, resistant vectors were younger than their susceptible counterparts; however, a small proportion of intensely resistant mosquitoes were older, which may be cause for concern. Further investigations are necessary to investigate the impact of insecticide resistance on vector fitness, including mosquito fecundity, egg viability, hatchability and parasite development following an infected blood meal.

\section{Methods}

\section{Study area and mosquito collections}

Mosquito collections were undertaken in six villages in the Maferinyah sub-prefecture, Forecariah Prefecture (Fandie, Madinagbe, Maferinyah Centre I, Moribayah, Senguelen and Yindi), in South-West Guinea. Deltamethrin treated bednets were distributed as part of a national mass campaign in Maferinyah in 2016. Sampling was conducted between $22^{\text {nd }}$ June and $17^{\text {th }}$ July 2017 , coinciding with the beginning of the long rainy season. Following consent from the household owner, indoor resting, female Anopheles mosquitoes were collected from house walls by manual aspiration between 7:00h and 12:00h. In the same villages, mosquitoes were also sampled using human landing catches, carried out between 22:00h and 3:00h. Mosquitoes were stored in cages with access to 10\% sugar solution, prior to transport to the Centre de Formation et de Recherche en Santé rurale de Maferinyah (CNFRSR) for analysis.

\section{$C D C$ resistance intensity and synergist bioassays}

All bioassays were performed using mosquitoes identified morphologically as An. gambiae s.l. ${ }^{56}$; wild caught females were held for a maximum of 48 hours before testing. Centers for Disease Control and Prevention (CDC) resistance intensity bioassays for three pyrethroid insecticides (alpha-cypermethrin, deltamethrin and permethrin) were conducted according to published guidelines ${ }^{52}$. Stock solutions of 1, 2, 5 and 10 times the diagnostic dose of insecticide (alpha-cypermethrin: $12.5 \mu \mathrm{g} / \mathrm{bottle}$; deltamethrin: $12.5 \mu \mathrm{g} / \mathrm{bottle}$; and permethrin: $21.5 \mu \mathrm{g} /$ bottle), were prepared by diluting technical grade insecticide in $50 \mathrm{ml}$ of acetone. Bioassays for bendiocarb were conducted using the diagnostic dose (1X: $12.5 \mu \mathrm{g} / \mathrm{bottle})$. The inside of each Wheaton $250 \mathrm{ml}$ bottle along with its cap was coated with $1 \mathrm{ml}$ of stock solution by rolling and inverting the bottles. In each test, a control bottle was coated with 1 $\mathrm{ml}$ of acetone. Following coating, bottles were left to dry in a dark box. Approximately 15-25 field-caught adult female An. gambiae s.l. of unknown age and mixed physiological status, were introduced into each bottle using a mouth aspirator and mortality was recorded at 15 min intervals until all were dead or up to two hours. In select sites with significant pyrethroid resistance, synergist assays were also conducted by pre-exposing mosquitoes to piperonyl butoxide (PBO) for 1 hour (100 $\mu \mathrm{g} / \mathrm{bottle}$ ) prior to performing bioassays. Multiple replicates were performed per insecticide and study village, depending on mosquito availability, and 
individual surviving (resistant) and dead (susceptible) mosquitoes were preserved in RNAlater ${ }^{\circledR}$ (Thermo Fisher Scientific, UK) at $-20^{\circ} \mathrm{C}$ at the London School of Hygiene and Tropical Medicine (LSHTM) and CDC. Prior to molecular analysis, mosquito head/thoraxes were separated from abdomens under a dissecting microscope and stored separately.

\section{Parity dissection}

Ovarian dissection to determine mosquito parity was performed on ten mosquitoes, selected randomly from each bottle after bioassay completion ${ }^{57}$. The ovaries of each mosquito were dissected on a sterile microscope slide in distilled water, using a binocular dissection microscope and physiological status was determined. The ovaries were then examined under a light microscope (10X magnification) for the presence of tightly coiled skeins or loose coils, indicative of a nulliparous or parous ovary, respectively. On completion of ovarian dissection, head/thoraxes and abdomens of each mosquito were stored separately in RNAlater $^{\circledR}$ (Thermo Fisher Scientific, UK) at $-20^{\circ} \mathrm{C}$.

\section{Molecular species identification}

A subset of susceptible and resistant An. gambiae s.l. mosquitoes from all six villages containing both nulliparous and parous individuals were selected for molecular analysis at the LSHTM and CDC. Genomic DNA from dissected body parts was extracted per protocol using Qiagen DNeasy 96 Blood and Tissue kits (Qiagen, UK) at LSHTM or Extracta ${ }^{\mathrm{TM}}$ DNA Prep for PCR-Tissue kits (QuantaBio, USA) at CDC.

At LSHTM, molecular species identification was performed using a multiplex TaqMan real time PCR assay to detect and discriminate An. gambiae and An. arabiensis ${ }^{58}$. PCR reactions were prepared using Qiagen Quantitect Probes Master mix (Qiagen) with each reaction containing $6.25 \mu \mathrm{l}$ of master mix, a final concentration of $0.8 \mu \mathrm{M}$ of each primer, $0.2 \mu \mathrm{M}$ of probe An. arabiensis (Cy5), 80nM of probe An. gambiae (FAM) and $1 \mu 1$ of template DNA for a a final reaction volume of $12.5 \mu$ l. Prepared reactions were run on a Stratagene Mx30005P QPCR system for $10 \mathrm{~min}$ at $95^{\circ} \mathrm{C}$, followed by 40 cycles of $95^{\circ} \mathrm{C}$ for $25 \mathrm{sec}$ and $66^{\circ} \mathrm{C}$ for $60 \mathrm{sec}$. The increases in the species-specific FAM and Cy5 fluorophores was detected in real-time at the end of each cycle and results were analysed using Stratagene MxPro QPCR software. Positive controls from gDNA extracted from known An. gambiae and An. arabiensis individuals were included in each run, in addition to no template controls (NTCs). Sub-samples of individuals from each district confirmed as An. gambiae were further distinguished as An. coluzzii or An. gambiae s.s by targeting a SINE2OO insertion only present in An. coluzzii ${ }^{47}$. PCR reactions were prepared using Hot Start Taq 2X Master Mix (New England Biolabs, UK) with each reaction containing $12.5 \mu 1$ of master mix, a final concentration of $1 \mu \mathrm{M}$ of each primer, $2 \mu 1$ template DNA for a final reaction volume of $25 \mu 1$. Prepared reactions were amplified using a BIORAD T100 Thermal Cycler for $10 \mathrm{~min}$ at $95^{\circ} \mathrm{C}$, followed by 35 cycles of $94^{\circ} \mathrm{C}$ for $30 \mathrm{sec}, 54^{\circ} \mathrm{C}$ for $30 \mathrm{sec}, 72^{\circ} \mathrm{C}$ for $1 \mathrm{~min}$ and a final extension of $72^{\circ} \mathrm{C}$ for $10 \mathrm{~min}$. PCR products were separated and visualised using $2 \%$ Egel EX agarose gels (Invitrogen, UK) with SYBR safe and an Invitrogen E-gel iBase RealTime Transilluminator. An. coluzzii individuals with the insertion resulted in a single PCR product of $479 \mathrm{bp}$ and An. gambiae s.s. a PCR product of $249 \mathrm{bp}$.

At CDC, An. coluzzii and An. gambiae s.s. specimens were differentiated by targeting single nucleotide polymorphisms (SNPs) present in rDNA $^{48}$. PCR reactions were prepared using 2040ng of DNA, 5X Green GoTaq ${ }^{\circledR}$ Reaction Buffer (Promega, USA), $25 \mathrm{mM} \mathrm{MgCl} 2,2.5 \mathrm{mM}$ 
of each dNTP, $1 \mathrm{U}$ GoTaq ${ }^{\circledR}$ DNA polymerase and $25 \mathrm{pmol} / \mu \mathrm{l}$ of primers IMP-UN, AR-3T, GA-3T, IMP-S1 and IMP-M1 in a final volume of $25 \mu 1$. PCR reaction conditions were $95^{\circ} \mathrm{C}$ for $5 \mathrm{~min}$, followed by 30 amplification cycles $\left(95^{\circ} \mathrm{C}\right.$ for $30 \mathrm{sec}, 58^{\circ} \mathrm{C}$ for $30 \mathrm{sec}, 72^{\circ} \mathrm{C}$ for 30 sec) and a final elongation step at $72^{\circ} \mathrm{C}$ for 5 min. Amplified PCR products were visualized on $1.5 \%$ agarose gels, stained with GelRed ${ }^{\mathrm{TM}}$ (Biotium, USA). An. arabiensis Dongola, An. coluzzii AKDR and An. gambiae s.s. RSP-ST strains from the Malaria Research and Reference Reagent Resource Center (MR4), were used as positive controls. Amplification products of $463 \mathrm{bp}$ and $333 \mathrm{bp}$ or $463 \mathrm{bp}$ and $221 \mathrm{bp}$ were indicative of An. coluzzii or $A n$. gambiae s.s., respectively.

\section{Insecticide target site mutation detection}

Detection of the L1014F West African $k d r$ mutation was performed on a subset of individuals from all six districts according to the adapted protocol for allele-specific PCR developed by Martinez-Torres et al. ${ }^{59}$. At both LSHTM and CDC, PCR reactions were prepared using Hot Start Taq 2X Master Mix (New England Biolabs) with each reaction containing $12.5 \mu 1$ of master mix and variable final concentrations of primers (IPCF $0.1 \mu \mathrm{M}$, AltRev $0.1 \mu \mathrm{M}$, West WT $1 \mu \mathrm{M}$, West West $1.1 \mu \mathrm{M}$ ) for a final reaction volume of $25 \mu 1$. Prepared reactions were run on a BIO-RAD QPCR system for $5 \mathrm{~min}$ at $95^{\circ} \mathrm{C}$, followed by 35 cycles of $95^{\circ} \mathrm{C}$ for 30 sec, $59^{\circ} \mathrm{C}$ for $30 \mathrm{sec}$ and $72^{\circ} \mathrm{C}$ for $30 \mathrm{sec}$ and a final extension of $72^{\circ} \mathrm{C}$ for $5 \mathrm{~min}$. PCR products were separated and visualised using $2 \%$ Egel EX agarose gels (Invitrogen) with SYBR safe and an Invitrogen E-gel iBase Real-Time Transilluminator. A PCR product of $214 \mathrm{bp}$ indicated the susceptible wild type allele and a PCR product of $156 \mathrm{bp}$ indicated the resistant allele. An. coluzzii AKDR and An. gambiae s.s. RSP-ST were used as positive and negative controls for L1014F $k d r$, respectively.

At LSHTM, a larger sub-sample of individuals from all six districts was chosen to be screened for the N1575Y mutation (previously shown to have low prevalence in West African populations) using the TaqMan real time PCR assay developed by Jones et al. ${ }^{29}$. PCR reactions were prepared using Qiagen Quantitect Probes Master mix (Qiagen) with each reaction containing $10 \mu \mathrm{l}$ of master mix, a final concentration of $1 \mu \mathrm{M}$ of each primer and $0.5 \mu \mathrm{M}$ of each probe, $5 \mu \mathrm{l}$ of PCR grade water and $2 \mu 1$ of template DNA, for a final reaction volume of $20 \mu 1$. Prepared reactions were run on a Roche LightCycler 96 System for 15 min at $95^{\circ} \mathrm{C}$, followed by 35 cycles of $94^{\circ} \mathrm{C}$ for $15 \mathrm{sec}$ and $60^{\circ} \mathrm{C}$ for $60 \mathrm{sec}$. Positive controls from gDNA extracted from known An. gambiae s.s. with or without the N1575 mutation were included on each run in addition to no template controls (NTCs). PCR results were analysed using the LightCycler 96 software (Roche Diagnostics).

At CDC, to detect the N1575Y mutation, a 218 bp fragment of the VGSC channel spanning domains III-IV was sequenced. PCR reactions were prepared using $25 \mu 1$ of $2 \mathrm{X}$ AccuStart ${ }^{\mathrm{TM}}$ II PCR SuperMix, a final concentration of $20 \mathrm{pmol} / \mu$ l of primers Exon_29_F (5'AAATGCTCAGGTCGGTAAACA-3') and Exon_29_R (5'GCCACTGGAAAGAATGGAAA-3') ${ }^{29}$ and $2 \mu$ l of template DNA, for a final reaction volume of $50 \mu \mathrm{l}$. PCR reaction conditions were $95^{\circ} \mathrm{C}$ for $3 \mathrm{~min}$, followed by 35 amplification cycles $\left(95^{\circ} \mathrm{C}\right.$ for $30 \mathrm{sec}, 58^{\circ} \mathrm{C}$ for $30 \mathrm{sec}, 72^{\circ} \mathrm{C}$ for $\left.30 \mathrm{sec}\right)$ and a final elongation step at $72^{\circ} \mathrm{C}$ for $5 \mathrm{~min}$. Amplified PCR products were visualized on $2 \%$ agarose gels, stained with GelRed $^{\mathrm{TM}}$ (Biotium, USA) and purified using the 96-well Millipore ${ }^{\mathrm{TM}}$ MultiScreen ${ }^{\mathrm{TM}}$ HTS vacuum manifold system. Bi-directional sequencing was performed using primers Exon_29_F and Exon_29_R with the BigDye ${ }^{\circledR}$ Terminator v3.1 Cycle Sequencing Kit 
(Applied Biosystems, USA) according to the manufacturer's protocol. Sequencing reactions were purified using the Big Dye ${ }^{\circledR}$ Xterminator ${ }^{\mathrm{TM}}$ Purification Kit (Applied Biosystems, USA), according to the manufacturer's protocol and data were generated using a $3500 \mathrm{xL}$ Genetic Analyzer (Applied Biosystems, USA). Sequences were assembled manually in BioEdit v7.0.9.0 sequence alignment editor software (Ibis Biosciences, USA) and unambiguous consensus sequences were produced for each individual. Consensus sequences are available from GenBank under the accession numbers MH929325 - MH929433.

The presence of the Ace-1 mutation was determined using PCR restriction fragment length polymorphism analysis ${ }^{60}$. At both LSHTM and CDC, PCR reactions were prepared using Hot Start Taq 2X Master Mix (New England Biolabs) with each reaction containing 12.5 $\mu 1$ of master mix, a final concentration of $1 \mu \mathrm{M}$ of each primer, $2 \mu 1$ template DNA, to a final reaction volume of $25 \mu 1$. Prepared reactions were run on a BIO-RAD QPCR system for 5 min at $95^{\circ} \mathrm{C}$, followed by 30 cycles of $95^{\circ} \mathrm{C}$ for $30 \mathrm{sec}, 52^{\circ} \mathrm{C}$ for $30 \mathrm{sec}$ and $72^{\circ} \mathrm{C}$ for $1 \mathrm{~min}$ and a final extension of $72^{\circ} \mathrm{C}$ for $5 \mathrm{~min}$. PCR products were digested using the AluI restriction enzyme through incubation at $37^{\circ} \mathrm{C}$ for $16 \mathrm{hr}$ followed by $65^{\circ} \mathrm{C}$ for $20 \mathrm{~min}$. DNA fragments were visualised on 2\% Egel EX agarose gels (Invitrogen) with SYBR safe and an Invitrogen E-gel iBase Real-Time Transilluminator. 194 bp undigested PCR products indicated the susceptible allele and $74 \mathrm{bp}$ and $120 \mathrm{bp}$ digested fragments indicated the presence of the resistant allele. Presence of all three product sizes indicated that the sample was heterozygote.

\section{Plasmodium falciparum detection}

Bisected mosquito head/thoraxes and abdomens were screened separately for $P$. falciparum infection, by targeting a $120 \mathrm{bp}$ sequence of the $P$. falciparum cytochrome c oxidase subunit 1 (coxl) mitochondrial gene ${ }^{61}$. At LSHTM real-time PCR reactions were prepared using FastStart SYBR Green Master mix (Roche Diagnostics) with each reaction containing $5 \mu 1$ of master mix, a final concentration of $1 \mu \mathrm{M}$ of each primer, $1 \mu 1$ of PCR grade water and $2 \mu \mathrm{l}$ template DNA, to a final reaction volume of $10 \mu 1$. Prepared reactions were run on a Roche LightCycler $96 \mathrm{System}$ for $15 \mathrm{~min}$ at $95^{\circ} \mathrm{C}$, followed by 35 cycles of $95^{\circ} \mathrm{C}$ for $15 \mathrm{sec}$ and $58^{\circ} \mathrm{C}$ for $30 \mathrm{sec}$. Amplification was followed by a dissociation curve $\left(95^{\circ} \mathrm{C}\right.$ for $10 \mathrm{sec}, 65^{\circ} \mathrm{C}$ for $60 \mathrm{sec}$ and $97^{\circ} \mathrm{C}$ for $1 \mathrm{sec}$ ) to ensure the correct target sequence was amplified. Positive controls from gDNA extracted from a cultured $P$. falciparum-infected blood sample (parasitaemia of $\sim 10 \%$ ) were included on each run, in addition to no template controls (NTCs). PCR results were analysed using the LightCycler@ 96 software (Roche Diagnostics). At CDC, a conventional PCR was used for coxl detection ${ }^{62}$. PCR reactions were prepared using $6.25 \mu 1$ of $2 \mathrm{X}$ AccuStart ${ }^{\mathrm{TM}}$ II PCR SuperMix, a final concentration of $5 \mu \mathrm{M}$ of primers COX-IF (5'-AGAACGAACGCTTTTA ACGCCTG-3') and COX-IR (5'-ACWGGATGGACTTTATATCCACCATTAAGT-3') ${ }^{62}$ and $2 \mu \mathrm{l}$ of template DNA, for a final reaction volume of $12.5 \mu \mathrm{l}$. PCR reaction conditions were $94^{\circ} \mathrm{C}$ for $5 \mathrm{~min}$, followed by 40 amplification cycles $\left(94^{\circ} \mathrm{C}\right.$ for $1 \mathrm{~min}, 62^{\circ} \mathrm{C}$ for $1 \mathrm{~min}$, $72^{\circ} \mathrm{C}$ for $1.5 \mathrm{~min}$ ) and a final elongation step at $72^{\circ} \mathrm{C}$ for $10 \mathrm{~min}$. Amplified PCR products were visualized on $2 \%$ agarose gels, stained with GelRed ${ }^{\mathrm{TM}}$ (Biotium, USA), alongside the same positive and negative controls used in the real-time assay. A positive head/thorax or abdomen was assumed to indicate the presence of sporozoites or oocysts, respectively. 


\section{Data analysis}

For all bioassays, mortality was corrected using Abbott's formula when mortality in the control group was greater than 5\% but less than 20\%; test results were discarded when control mortality was greater than $20 \%{ }^{63}$. Percentage mosquito mortality for each insecticide dose was interpreted using the updated WHO criteria: 98-100\% mortality at 30 minutes of exposure indicates 'susceptibility', 90-97\% mortality suggests 'possible resistance' and $<90 \%$ indicates the presence of 'resistance' ${ }^{53}$. Pearson's Chi squared tests and Fisher's exact tests (when sample sizes were small) were used to investigate the statistical association between various biological variables; the former was also used to detect deviations from Hardy-Weinberg equilibrium. Outcomes from pyrethroid bioassays were evaluated separately to carbamate assays, unless otherwise specified. All statistical analyses were performed in Stata/IC 15.0 (Stata Corp., College Station, USA) with the level of significance set at $\alpha=0.05$.

\section{Ethical approval and consent to participate}

The study protocol was reviewed and approved by the Comite National d'Ethique pour la Recherche en Sante (030/CNERS/17) and the institutional review boards (IRB) of the London School of Hygiene and Tropical Medicine (\#13612 and \#14076) and the Centers for Disease Control and Prevention, USA (2018-086). Prior to study initiation, community consent was sought from village leaders and written, informed consent was obtained from the heads of all households selected for participation. Study information was provided to participants in French, Susu, Foula and Malinké. Fieldworkers participating in human landing catches were provided with doxycycline malaria prophylaxis for the duration of the study.

\section{References}

1. $\quad$ Organization, W. H. World Malaria Report 2017. (2017).

2. World Health Organization. World Malaria Report 2016. World Health Organization (2016). doi:10.1071/EC12504

3. Ranson, H. N'guessan, R. Lines, J. Moiroux, N. Nkuni, Z. Corbel, V. Pyrethroid resistance in African anopheline mosquitoes: what are the implications for malaria control? Trends Parasitol. 27, 91-98 (2011).

4. Strode, C., Donegan, S., Garner, P., Enayati, A. A. \& Hemingway, J. The Impact of Pyrethroid Resistance on the Efficacy of Insecticide-Treated Bed Nets against African Anopheline Mosquitoes: Systematic Review and Meta-Analysis. PLoS Med. 11, (2014).

5. Hemingway, J. et al. Tools and Strategies for Malaria Control and Elimination: What Do We Need to Achieve a Grand Convergence in Malaria? PLoS Biol. 14, 1-14 (2016).

6. Kleinschmidt, I. et al. Design of a study to determine the impact of insecticide resistance on malaria vector control: a multi-country investigation. Malar. J. 14, 282 (2015).

7. Lindblade, K. A. et al. A cohort study of the effectiveness of insecticide-treated bed nets to prevent malaria in an area of moderate pyrethroid resistance, Malawi. Malar. J. 14, 31 (2015).

8. Henry, M. C. et al. Protective efficacy of lambda-cyhalothrin treated nets in Anopheles 
gambiae pyrethroid resistance areas of Cote d'Ivoire. Am J Trop Med Hyg 73, 859864 (2005).

9. Asidi, A., N'Guessan, R., Akogbeto, M., Curtis, C. \& Rowland, M. Loss of household protection from use of insecticide-treated nets against pyrethroid-resistant mosquitoes, Benin. Emerg. Infect. Dis. 18, 1101-1106 (2012).

10. Ochomo, E. et al. Insecticide-Treated Nets and Protection against InsecticideResistant Malaria Vectors in Western Kenya. Emerg. Infect. Dis. 23, 158-764 (2017).

11. Damien, G. B. et al. Malaria infection and disease in an area with pyrethroid-resistant vectors in southern Benin. Malar. J. 9, 380 (2010).

12. Tokponnon, F. T. et al. Impact of long-lasting, insecticidal nets on anaemia and prevalence of Plasmodium falciparum among children under five years in areas with highly resistant malaria vectors. Malar. J. 13, 76 (2014).

13. Chanda, E. et al. Insecticide resistance and the future of malaria control in Zambia. PLoS One 6, 1-9 (2011).

14. Kleinschmidt, I. et al. Articles Implications of insecticide resistance for malaria vector control with long-lasting insecticidal nets : a WHO-coordinated, prospective , international, observational cohort study. 3099, 1-10 (2018).

15. Viana, M., Hughes, A., Matthiopoulos, J., Ranson, H. \& Ferguson, H. M. Delayed mortality effects cut the malaria transmission potential of insecticide-resistant mosquitoes. Proc. Natl. Acad. Sci. 113, 8975-8980 (2016).

16. Alout, H. et al. Interactive cost of Plasmodium infection and insecticide resistance in the malaria vector Anopheles gambiae. Sci. Rep. 6, 29755 (2016).

17. Siegert, P. Y. Walker, E. Miller, J. R. Differential behavioral responses of Anopheles gambiae (Diptera: Culicidae) modulate mortality caused by pyrethroid-treated bednets. J. Econ. Entomol. 102, 2061-2071 (2009).

18. Diop, M. M. et al. Behavioral cost \& overdominance in anopheles gambiae. PLoS One 10, 1-12 (2015).

19. Platt, N. et al. Target-site resistance mutations (kdr and RDL), but not metabolic resistance, negatively impact male mating competiveness in the malaria vector Anopheles gambiae. Heredity (Edinb). 115, 243-252 (2015).

20. Kristan, M. et al. Exposure to deltamethrin affects development of Plasmodium falciparum inside wild pyrethroid resistant Anopheles gambiae s.s. mosquitoes in Uganda. Parasit. Vectors 9, 100 (2016).

21. Alout, H. et al. Insecticide exposure impacts vector-parasite interactions in insecticideresistant malaria vectors. Proc. R. Soc. B Biol. Sci. 281, 20140389-20140389 (2014).

22. Alout, H. et al. Insecticide Resistance Alleles Affect Vector Competence of Anopheles gambiae s.s. for Plasmodium falciparum Field Isolates. PLoS One 8, (2013).

23. Paludisme, M. de la S. D. N. de la P. et de la S. C. P. N. de L. C. le. Plan strategique national de lutte contre le paludisme 2018-2022. (2017).

24. Initiative, P. M. Guinea Malaria Operational Plan FY 2017. (2017).

25. Paludisme, P. N. de L. contre le. Rapport technique: Etude de sensibilité des vecteurs du paludisme aux insecticides dans le district sanitaire de Boffa. (2012).

26. Keita, K. et al. Species Identification and Resistance Status of Anopheles gambiae s.1. (Diptera: Culicidae) Mosquitoes in Guinea. J. Med. Entomol. 54, 677-681 (2017).

27. Lehmann, T. Diabate, A. The molecular forms of Anopheles gambiae: A phenotypic perspective Tovi. Infect. Genet. Evol. 8, 737-746 (2008).

28. Toé, K. H., N'Falé, S., Dabiré, R. K., Ranson, H. \& Jones, C. M. The recent escalation in strength of pyrethroid resistance in Anopheles coluzzi in West Africa is linked to increased expression of multiple gene families. BMC Genomics 16, 146 (2015).

29. Jones, C. M. et al. Footprints of positive selection associated with a mutation 
(N1575Y) in the voltage-gated sodium channel of Anopheles gambiae. Proc. Natl. Acad. Sci. 109, 6614-6619 (2012).

30. Harris, A. F., Rajatileka, S. \& Ranson, H. Pyrethroid resistance in Aedes aegypti from Grand Cayman. Am. J. Trop. Med. Hyg. 83, 277-284 (2010).

31. Xu, J. et al. Multi-country Survey Revealed Prevalent and Novel F1534S Mutation in Voltage-Gated Sodium Channel (VGSC) Gene in Aedes albopictus. PLoS Negl. Trop. Dis. 10, 1-12 (2016).

32. Reimer, L. et al. Relationship Between kdr Mutation and Resistance to Pyrethroid and DDT Insecticides in Natural Populations of Anopheles gambiae. J. Med. Entomol. 45, 260-266 (2008).

33. Assogba, B. S. et al. An ace-1 gene duplication resorbs the fitness cost associated with resistance in Anopheles gambiae, the main malaria mosquito. Sci. Rep. 5, 19-21 (2015).

34. Djogbenou, L. et al. Costs of insensitive acetylcholinesterase insecticide resistance for the malaria vector Anopheles gambiae homozygous for the G119S mutation. Malar. J. 9, 12 (2010).

35. Alout, H., Djogbénou, L., Berticat, C., Chandre, F. \& Weill, M. Comparison of Anopheles gambiae and Culex pipiens acetycholinesterase 1 biochemical properties. Comp. Biochem. Physiol. - B Biochem. Mol. Biol. 150, 271-277 (2008).

36. Assogba, B. S. et al. The ace-1 Locus Is Amplified in All Resistant Anopheles gambiae Mosquitoes: Fitness Consequences of Homogeneous and Heterogeneous Duplications. PLoS Biol. 14, 1-26 (2016).

37. Alout, H. et al. Interplay between Plasmodium infection and resistance to insecticides in vector mosquitoes. J. Infect. Dis. 210, 1464-1470 (2014).

38. Jones, C. M. et al. Aging partially restores the efficacy of malaria vector control in insecticide-resistant populations of Anopheles gambiae s.l. from Burkina Faso. Malar. J. 11, 24 (2012).

39. Rowland, M. \& Hemingway, J. Changes in malathion resistance with age in Anopheles stephensi from Pakistan. Pestic. Biochem. Physiol. 28, 239-247 (1987).

40. Lines, J. \& Nassor, N. DDT resistance in Anopheles gambiae declines with mosquito age. Med. Vet. Entomol. 5, 261-265 (1991).

41. MH, H. \& Curtis, C. Evaluation of the effect of mosquito age and prior exposure to insecticide on pyrethroid tolerance in Anopheles mosquitoes (Diptera: Culicidae). Bull. Entomol. Res. 89, 329-337 (1999).

42. S, R., J, B. \& Ranson, H. Mosquito age and susceptibility to insecticides. Trans. $R$. Soc. Trop. Med. Hyg. 105, 247-253 (2011).

43. Glunt, K. D., Thomas, M. B. \& Read, A. F. The effects of age, exposure history and malaria infection on the susceptibility of Anopheles mosquitoes to low concentrations of pyrethroid. PLoS One 6, (2011).

44. RH, H., BD, B., C, P., LL, K. \& Coetzee, M. Laboratory selection for and characteristics of pyrethroid resistance in the malaria vector Anopheles funestus. Med. Vet. Entomol. 19, 271-275 (2005).

45. Guedes, R. N. C., Walse, S. S. \& Throne, J. E. Sublethal exposure, insecticide resistance, and community stress. Curr. Opin. Insect Sci. 21, 47-53 (2017).

46. Coulibaly, B. et al. Malaria vector populations across ecological zones in Guinea Conakry and Mali, West Africa. Malar. J. 15, 191 (2016).

47. Santolamazza, F. et al. Insertion polymorphisms of SINE200 retrotransposons within speciation islands of Anopheles gambiae molecular forms. Malar. J. 7, 163 (2008).

48. Wilkins, E. E., Howell, P. I. \& Benedict, M. Q. IMP PCR primers detect single nucleotide polymorphisms for Anopheles gambiae species identification, Mopti and 
Savanna rDNA types, and resistance to dieldrin in Anopheles arabiensis. Malar. J. 5, 125 (2006).

49. Crawford, J. E. et al. Evolution of GOUNDRY, a cryptic subgroup of Anopheles gambiae s.1., and its impact on susceptibility to Plasmodium infection. Mol. Ecol. 25, 1494-1510 (2016).

50. Riehle, M. M. et al. The anopheles gambiae 2La chromosome inversion is associated with susceptibility to Plasmodium falciparum in Africa. Elife 6, 1-24 (2017).

51. Riehle, M. M. et al. A cryptic subgroup of Anopheles gambiae is highly susceptible to human malaria parasites. Science (80-. ). 331, 596-598 (2011).

52. Centers for Disease Control and Prevention. Guideline for Evaluating Insecticide Resistance in Vectors Using the CDC Bottle Bioassay. CDC Methods 1-28 (2012).

53. World Health Organization. Test procedures for insecticide resistance monitoring in malaria vector mosquitoes. World Heal. Organ. Tech. Rep. Ser. 22 (2013). doi:10.1007/978-3-642-10565-4

54. Spillings, B. L., Coetzee, M., Koekemoer, L. L. \& Brooke, B. D. The effect of a single blood meal on the phenotypic expression of insecticide resistance in the major malaria vector Anopheles funestus. Malar. J. 7, 226 (2008).

55. Foley, D. H. et al. Mosquito bisection as a variable in estimates of PCR-derived malaria sporozoite rates. Malar. J. 11, 1-7 (2012).

56. Gillies, M. T. \& Coetzee, M. A supplement of the Anopheles of Africa south of the Sahara (Afrotropical Region). Publ. South African Inst. Med. Res. No. 55 (1987).

57. Detinova, T. S. Age grading methods in Diptera of medical importance with special reference to some vectors of malaria. Monogr Ser World Heal. Organ 47, 13-191 (1962).

58. Bass, C., Williamson, M. S., Wilding, C. S., Donnelly, M. J. \& Field, L. M. Identification of the main malaria vectors in the Anopheles gambiae species complex using a TaqMan real-time PCR assay. Malar. J. 6, 155 (2007).

59. Martinez-Torres D, Chandre F, Williamson MS, Darriet F, Bergé JB, Devonshire AL, Guillet P, Pasteur N, P. D. Molecular characterization of pyrethroid knockdown resistance (kdr) in the major malaria vector Anopheles gambiae s.s. Insect Mol. Biol. 7, 179-84 (1998).

60. Weill, M. et al. The unique mutation in ace-1 giving high insecticide resistance is easily detectable in mosquito vectors. Insect Mol. Biol. 13, 1-7 (2004).

61. Marie, A. et al. Evaluation of a real-time quantitative PCR to measure the wild Plasmodium falciparum infectivity rate in salivary glands of Anopheles gambiae. Malar. J. 12, 224 (2013).

62. Echeverry, D. F. et al. Fast and robust single PCR for Plasmodium sporozoite detection in mosquitoes using the cytochrome oxidase I gene. Malar. J. 1-8 (2017). doi:10.1186/s12936-017-1881-1

63. Abbott, W. S. A method of computing the effectiveness of an insecticide. J. Econ. Entomol. 18, 265-267 (1925).

\section{Acknowledgements}

The authors express their sincere thanks to the entomology fieldworkers and the residents of Forecariah Prefecture for their study participation; to Luc Djogbenou and Corine Ngufor for providing G119S Ace-1 controls; to Martin Donnelly for providing N1575Y controls; to Dustin Miller for providing An. arabiensis, An. coluzzii and An. gambiae s.s. controls; to 
Alice Sutcliffe for providing primers and reagents; and to Jo Lines and Cheryl Whitehorn for providing training and support. Study funding was provided by a Royal Society of Tropical Medicine and Hygiene small grant, a Sir Halley Stewart Trust grant, a L'Oreal-UNESCO for Women in Science UK and Ireland Fellowship awarded to LAM, individual Bayer Vector Control Research and Travel grants awarded to EC and NMV, the Helena Vrbova scholarship awarded to NMV and a Wellcome Trust /Royal Society grant awarded to TW (101285/Z/13/Z): http://www.wellcome.ac.uk; https://royalsociety.org.

\section{Author Contributions}

LAM, TW, MS and AHB designed the study and were responsible for data analysis and interpretation. EC, NMV and MS led the entomology field activities and participated in data collection. EC, NVM, TW, JO and LAM performed the molecular assays. LAM, TW, EC and NMV drafted the manuscript which was revised by co-authors. All authors read and approved the final manuscript.

\section{Additional Information}

Competing Interests: The authors declare that they have no competing interests. 